\title{
Seasonal Natural and Fishing Mortality of Striped Bass in a Southeastern Reservoir
}

\author{
Jessica S. Thompson, ${ }^{*}$ D. Scott Waters, ${ }^{1}$ and James A. Rice \\ Department of Zoology, North Carolina State University, \\ Campus Box 7617, Raleigh, North Carolina 27695-7617, USA \\ Joseph E. Hightower \\ U.S. Geological Survey, North Carolina Cooperative Fish and Wildlife Research Unit, \\ Department of Zoology, North Carolina State University, \\ Campus Box 7617, Raleigh, North Carolina 27695-7617, USA
}

\begin{abstract}
Reliable estimates of natural and fishing mortality are important for management of exploited fish populations, but these components of the total mortality rate can be difficult to determine by traditional fisheries methods. We used telemetry data to determine seasonal instantaneous fishing $(F)$ and natural mortality $(M)$ rates of subadult and adult striped bass Morone saxatilis in Badin Lake, North Carolina. Our analyses were based on the fates of 64 fish implanted with sonic transmitters and released and tracked for 2 years. Natural mortality was low and constant during the course of the study $(M \pm \mathrm{SE}=0.10 \pm 0.01)$ and was similar to estimates for other reservoir populations of striped bass. A natural mortality rate of $0.09-0.16$ may be a reasonable approximation for populations across the southeastern United States. Fishing mortality varied seasonally and was highest in the spring and summer of 2002 and the summer and fall of 2003; annual fishing mortality $(F \pm \mathrm{SE}$ ) was $0.65 \pm 0.08$ in 2002 and $0.77 \pm 0.08$ in 2003 . Due to these high harvest rates, estimated annual survival rates were low for the Badin Lake population (47\% in 2002; $42 \%$ in 2003). Results of a yield-per-recruit model suggest that harvest of older, larger individuals can be increased in Badin Lake with a decrease in fishing mortality or a moderate increase in the minimum size limit, even when the effect of catch-and-release mortality of fish below the size limit is considered. Our results also indicate important considerations for researchers using this method in the future, including the need to estimate downstream emigration and delay the inclusion of newly tagged fish in analysis to avoid biasing estimates of fishing mortality.
\end{abstract}

Separating mortality of exploited fish populations into natural and harvest-related components can be critical for effective fisheries management. The influence of harvest regulations on the size composition and total weight of harvested fish will depend on, among other factors, the magnitude of natural mortality in comparison with the magnitude and, in some cases, seasonality of fishing mortality. Unfortunately, distinguishing between natural and fishing mortality is difficult, and traditional fisheries-based approaches, such as catch curve analysis or regression of the instantaneous total mortality rate $(M)$ on fishing effort (Vetter 1988), are subject to constraints not reasonably achieved for many populations. Tag return models (e.g., Brownie et al. 1985; Pollock et al. 1991; Hoenig et al. 1998a, 1998b) can be used to differentiate sources of mortality only if an auxiliary estimate of fishing

\footnotetext{
* Corresponding author: jessica_thompson@ncsu.edu

${ }^{1}$ Present address: Kansas Department of Wildlife and Parks, 2131180 Road, Glen Elder, Kansas 67446, USA.
}

Received March 16, 2006; accepted September 24, 2006 Published online May 7, 2007 effort is available or if the tag reporting rate is known. Obtaining reliable information on fishing effort, such as through a creel survey, requires time and money (Ney 1999), and the resulting estimate of fishing effort may not be applicable to other time periods or other systems. Similarly, accurate estimation of the tag reporting rate is dependent on assumptions that can be difficult to meet (Pollock et al. 1991, 2001).

These limitations have led to the development of telemetry methods based on relocating tagged animals at fixed time intervals to determine whether each animal has survived the time interval or has died (Trent and Rongstad 1974; Pollock et al. 1989, 1995). While these methods require extensive effort, they allow for direct differentiation between sources of mortality and provide information on the seasonality of these processes. Information on habitat selection and migration routes can also be obtained at the same time that data are collected for mortality estimation. These advantages have led to the widespread use of telemetry methods in terrestrial wildlife studies.

Applying telemetry methods to aquatic systems can be more difficult than in a terrestrial setting because fish cannot be observed directly, so the fate of each 


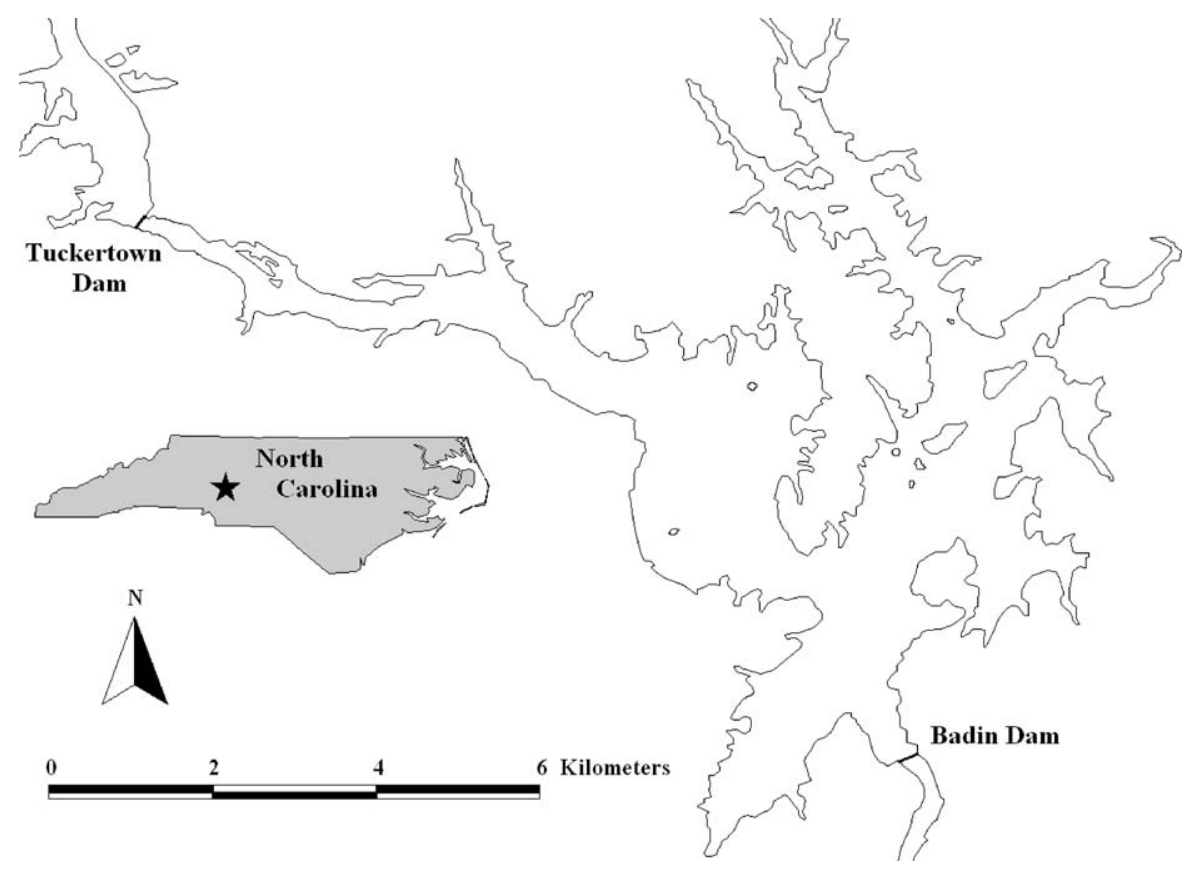

FIGURE 1.-Map of Badin Lake, North Carolina, where fishing and natural mortality rates of striped bass were assessed.

individual must be inferred based on movement. Hightower et al. (2001) developed a model to estimate fishing and natural mortality based on such indirect inferences. Fish that changed locations between search occasions were assumed to be alive. Fish that were relocated repeatedly at the same location were assumed to have died of natural causes or as a result of catchand-release mortality. Fish that disappeared from the system were assumed to have been caught or emigrated; in cases where emigration was low or could be estimated, fish disappearances then provided information about the harvest rate. Hightower et al. (2001) applied this model to the population of striped bass Morone saxatilis in Lake Gaston, North CarolinaVirginia, and succeeded in estimating the seasonal patterns of natural and fishing mortality. This approach has since been used to estimate natural and fishing mortality of juvenile blacktip sharks Carcharhinus limbatus along the Florida coast (Heupel and Simpfendorfer 2002) and largemouth bass Micropterus salmoides in a Puerto Rican reservoir (Waters et al. 2005), and a model combining the use of telemetry and tag return data to estimate natural and fishing mortality rates has been developed (Pollock et al. 2004).

We used this telemetry approach to estimate seasonal natural and fishing mortality rates of striped bass in Badin Lake, North Carolina. Having information about fishing and natural mortality from several reservoir populations should provide fishery managers with a solid foundation for management. To demonstrate how such mortality estimates can be used to inform management decisions, we constructed a seasonal yield-per-recruit model that shows the potential to increase yield and harvest of older fish in this fishery. We also estimated the effect of incorrect assumptions regarding fish harvest on estimates of fishing mortality; this source of uncertainty has not been characterized in previous uses of this approach. Our results indicate additional important considerations (e.g., downstream emigration, use of a 1-month waiting period before introducing newly tagged fish into the analysis) that will need to be addressed in future applications of this technique.

\section{Study Site}

Badin Lake (also known as Narrows Reservoir) is a 2,165-ha, moderately eutrophic reservoir located on the Yadkin River, a major tributary of the Pee Dee River in the Piedmont region of North Carolina (Figure 1). Badin Lake was impounded in 1917 for the purpose of hydroelectric power generation and is one of a series of impoundments on the Yadkin River. The reservoir has a mean depth of $21 \mathrm{~m}$, a maximum depth of $54 \mathrm{~m}$, and areas of littoral habitat as well as steep-sided regions. The pelagic forage base is composed primarily of threadfin shad Dorosoma petenense. Due to eutrophic 
conditions, Badin Lake experiences summer stratification in which epilimnetic temperatures commonly reach $28-30^{\circ} \mathrm{C}$ and dissolved oxygen drops below 2 $\mathrm{mg} / \mathrm{L}$ within $5 \mathrm{~m}$ of the surface (Thompson et al. 2005). Despite these extreme summer conditions, Badin Lake supports a relatively healthy striped bass population. Fish tend to have relative weights (Anderson and Neumann 1996) in the range of 80-100 (Thompson et al. 2005), and the active recreational fishery on the reservoir is regulated by a minimum size limit of 406 $\mathrm{mm}$ and a daily creel limit of eight fish. The lake does experience occasional summer mortality of striped bass, and the population does not contain many larger (>650 mm) or older (>age 4) individuals (Thompson et al. 2005).

\section{Methods}

Field methods.-Initial fish collection for tagging occurred during December 2001 through May 2002. While several early fish were collected by angling, the majority of fish were obtained by electrofishing in the tailrace of Tuckertown Dam, located at the upstream end of Badin Lake (Figure 1). Additional fish were tagged during February 2003 through April 2003 to increase the sample size for the second year of the study. Two of these fish were obtained from anglers, but the remaining fish tagged in the second year were collected by electrofishing below Tuckertown Dam.

Striped bass of legal size were anesthetized with MS-222 (tricaine methanesulfonate) at a concentration of $120 \mathrm{mg}$ of MS-222/L of water and tagged internally with one of two sizes of ultrasonic transmitters following the methods of Haeseker et al. (1996). The smaller transmitter (Sonotronics, Inc., Tucson, Arizona; Model IT-95-2; 7-g weight in water) was used for smaller fish $(<1 \mathrm{~kg})$. In addition, some larger fish were tagged with the smaller transmitter so that they could also be implanted with an archival temperature and depth tag (Star-Oddi, Reykjavik, Iceland; Model DST milli; 5-g weight in water) without the total tag weight exceeding $1.5 \%$ of their body weight. The Sonotronics IT-95-2 tags were programmed with a 1-week-on, 1week-off transmit schedule to extend the battery life to 2 years. The larger tag (Sonotronics CTT-83-3; 8-g weight in water) had temperature sensing capabilities and had a continuous transmit state with a battery life of 3 years. The archival tags and temperature sensing function of the larger ultrasonic tags were used as part of a study of habitat selection by these same striped bass (Thompson et al. 2005).

All fish were also tagged externally with a Floy internal anchor tag (Floy Tag, Inc., Seattle, Washington; Model FM-95W) to increase the chance that anglers would return the internal tags. The presence of an external tag may affect the behavior of the angler in terms of whether the fish is released or harvested, and this concern led Hightower et al. (2001) and Waters et al. (2005) to choose not to use external tags. However, the internal archival tags had high monetary and informational value, so we chose to use external tags in an effort to increase the transmitter return rate. We attempted to assess whether the presence of the external tag affected angler behavior by asking anglers returning tagged fish whether they would have kept the fish if a tag was not present. Signs announcing the study were posted at access points, and anglers returning the entire tagged fish received a small, variable reward (US\$10-50).

Only fish that survived and remained in the reservoir for the first month after tagging were considered in the data analysis. This constraint was intended to prevent inclusion of fish that may have died from surgeryrelated complications or fish whose initial behavior was altered because of the tagging procedure. Fish meeting this criterion were relocated biweekly except during a period of extremely low water in late summer 2002, when a monthly time period between relocations was necessary. No fish were harvested or died of natural causes during this low-water period, so the same relocation data were used for both biweekly periods within the month to prevent mortality estimates from being affected by this change in relocation schedule. Fish were tracked through January 2004 to provide accurate estimates through the end of 2003. Because each sonic tag transmitted a unique code, individual fish could be differentiated and relocation data were tabulated as individual relocation histories.

Interpretation and analysis of relocation data.-We used the approach of Hightower et al. (2001) to estimate fishing and natural mortality rates. Fish that changed positions between relocations were assumed to be alive. Fish that remained at the same location on multiple consecutive relocation dates were assumed to have died of natural causes, although catch-and-release mortality cannot be ruled out. Transmitter loss could also potentially explain a signal repeatedly located in the same position. While we are unaware of any study specifically addressing transmitter loss in striped bass, loss was low in a study of hybrid striped bass implanted with simulated radio transmitters (Walsh et al. 2000). Among fish tagged and held at low temperatures $\left(12-18^{\circ} \mathrm{C}\right)$ similar to the water temperatures at the time of tagging in this study, 3.3\% experienced transmitter loss. Of the fish whose surgeries involved absorbable sutures of the type used in this study, only $1.7 \%$ experienced transmitter loss (Walsh et al. 2000). Therefore, we feel that the 
likelihood of fish experiencing transmitter loss being incorrectly assigned as natural mortalities is quite low.

A fish that was not relocated on a given date could have been (1) present but its signal was missed, in which case it might be relocated at a later date, or (2) harvested, in which case it would not be detected again. Emigration or tag failure could also explain a recurrent missed signal. We attempted to control for emigration by searching for tagged fish on three occasions in the two reservoirs downstream from Badin Lake. A search of the third reservoir downstream from Badin Lake was also conducted at the end of the study. Fish found in these downstream systems were censored, meaning that they were removed from analysis on their last relocation date so that they were not incorrectly assumed to be fishing mortalities. As with any telemetry study, we had no foolproof way to measure the probability of tag failure, but we believe this probability is low because tags from all dead fish in the system (four natural mortalities and six surgery-related mortalities) remained audible through the end of the study. In addition, we did not observe an increase in missing fish toward the end of the study, as might occur if numerous tag batteries failed prematurely.

Estimates of natural and fishing mortality and relocation probability for each sampling period were based on the expected probability of survival for all fish released at time $i$ (Hightower et al. 2001). All fish found at time $i-1$ became part of the release $R_{i}$ at time $i$, such that each "release" included fish present in the system and relocated on the previous search occasion as well as newly tagged fish. Newly tagged fish were introduced to the analysis in the first release 1 month after their tagging date rather than in the release immediately after tagging. The use of this 1-month "quarantine" period was a modification of the technique of Hightower et al. (2001) that was necessary because our spring tagging efforts coincided with periods of high harvest. Fish disappearing from a study area within a month of tagging are frequently excluded from analyses aimed at estimating mortality rates under the assumption that their behavior (likelihood of emigrating or being harvested) is affected by the tagging process. Excluding fish that emigrated from the study area would not bias mortality estimates. However, several of our tagged fish were relocated at least once but disappeared from the reservoir within a month of tagging. These fish were not found in downstream reservoirs and, because of high harvest rates during these times, it is likely that these fish were harvested. In this case, preferential exclusion of these fish while including fish that survived their first month would cause the fishing mortality rate to be negatively biased during this interval. For example, assume that
10 tagged fish from year 1 remain in the lake and an additional 10 fish are tagged and released in January of year 2. Assume that 2 fish are harvested from each group in January so that 4 of 20 total fish (20\%) are harvested. Under the quarantine approach, the fishing mortality rate estimate for January would be based only on the 10 fish remaining from year 1 (i.e., 2 of 10 fish, or $20 \%$, were harvested), whereas Hightower et al. (2001) would have included the 8 fish that survived to February but would have excluded the 2 fish that disappeared because they did not survive for 1 month. In this case, 2 of 18 fish (11\%) would be assumed harvests. Introducing fish into the analysis only after the 1-month quarantine period eliminates this bias by only considering the fate of each fish subsequent to the month posttagging.

The expected number of fish in release $R_{i}$ that were first relocated alive on search occasion $i+1$ was given by the equation

$$
R_{i} \times \exp \left(-F_{i}-M_{i}\right) \times p_{i+1},
$$

where $F_{i}$ and $M_{i}$ are the instantaneous rates of fishing and natural mortality at time $i$, respectively, and $p_{i+1}$ is the relocation probability at time $i+1$. The expected number of fish from release $R_{i}$ that died from natural causes and were first relocated on search occasion $i+1$ was given by

$$
R_{i} \times M_{i} \times\left[\frac{1-\exp \left(-F_{i}-M_{i}\right)}{F_{i}+M_{i}}\right] \times p_{i+1}
$$

where all parameters are as defined above. These expressions were expanded for the expected number of fish from release $R_{i}$ found alive or dead on later search occasions (Hightower et al. 2001). We constructed expressions for the first three search occasions after each release, except in cases when fish were first relocated more than three search dates later; for two release dates each, fish were first found four or five search occasions later.

Individual relocation histories were transformed into a table known as a full- $m$ array (Burnham et al. 1987), which summarized the observed number of fish falling into each of the model probability categories for each release. The full- $m$ array and associated probability expressions were used in the computer program SURVIV (White 1983) to generate parameter estimates by maximum likelihood methods. Relocation probability was allowed to vary for each relocation date because initial data exploration suggested high variability in relocation probability. Fishing and natural mortality estimates were allowed to vary over several time periods: by individual search occasion, monthly, bimonthly, quarterly, annually, and constant over both 
years. The bimonthly schedule grouped January with February, March with April, and so on. The quarterly schedule grouped December through February, March through May, June through August, and September through November. These quarterly groupings were chosen to reflect both the seasonality of environmental conditions that might affect natural mortality rates and seasonal changes in angling pressure that might affect fishing mortality rates. For example, fishing pressure is often high during the spring congregation of fish in the Tuckertown Dam tailrace, which typically occurs between March and May. The summer months of June through August are a time of high boating and angling activity on the reservoir, and these months are the warmest of the year, which may affect the natural mortality rate of striped bass. Conversely, December, January, and February are the coldest months of the year, potentially also influencing natural mortality rates.

Akaike information criterion (AIC) values obtained from SURVIV were then used in model selection. The AIC provides a benefit for model fit and a penalty for overparameterization, allowing the full model with all parameters estimated for each relocation occasion to be compared with reduced models that group mortality estimates over time; the model with the lowest AIC value represents the best model by this criterion (Akaike 1973, cited by Williams et al. 2002). Asymptotic estimates of variance reported by SURVIV were used to determine the standard error of mortality estimates generated by the best model.

In addition, Fisher's exact test was used to determine whether the probability of a fish being harvested was dependent on that fish's sex or total length (TL) at tagging (in 100-mm increments). This test was chosen because the sample sizes in each sex and size category were insufficient for use of the telemetry model to estimate the fishing mortality rate of each stratum.

Effect of errors in assumed fish fates on fishing mortality estimates.-We consider it reasonable to assume that all fish that were no longer audible in Badin Lake and that were not located in downstream reservoirs were harvested. Nevertheless, there is a possibility in any study of this type that fish assumed to have been harvested actually emigrated or experienced tag failure. It is therefore important to assess the sensitivity of fishing mortality rates estimated using the telemetry-based approach to incorrect assumptions regarding harvest. We conducted two analyses using the relocation data from 2003 in which a number of fish that were assumed to have been harvested were instead censored. Fishing mortality rates were then estimated using the best model chosen for the original data, and these rates were compared with the original mortality rate estimates. In the first analysis, up to $50 \%$ of assumed harvests were censored across the year to determine the effect on the annual instantaneous fishing mortality rate for 2003 . The censored fish were distributed across the year to maintain a similar percent change in the number of harvests in each quarter. Quarters with a larger number of harvests would therefore have a larger number of censored fish. In the second analysis, up to $50 \%$ of assumed harvests were censored in each quarter of 2003 to determine the effect on the monthly instantaneous fishing mortality rate for that quarter. For each quarter, we repeated the analysis by varying the release date on which the fish were censored to determine whether the timing of the changed fish fates had an effect on the new monthly mortality rate estimate.

Observed age composition versus expected age composition based on mortality rates.-We compared the observed age composition of the Badin Lake striped bass population with the age composition calculated using the estimated mortality rates as a means to verify that our mortality estimates were within a reasonable range for the population. The observed age distribution for age- 2 and older fish in each age-class was determined based on aging of sagittal otoliths from 347 striped bass collected in gill nets between 2000 and 2003 (Thompson et al. 2005). Nets (5.1- and 7.6-cm bar mesh) were set opportunistically at locations throughout the reservoir in early summer (June or July), early fall (September), and winter (December) of each year, and age composition data indicated that fish were fully recruited to the smaller-mesh nets by age 2 (Thompson et al. 2005).

The expected age distribution for age- 2 and older fish, based on our telemetry results, was determined using the average of the annual instantaneous total mortality rates $(Z)$ estimated for 2002 and 2003. Fish reach legal size just before age 2 (Thompson et al. 2005), so age- 2 and older fish should experience both natural and fishing-related mortality. Starting with 100 age-2 fish, the number in each subsequent age-class was calculated as

$$
N_{a+1}=N_{a} \times \exp (-Z),
$$

where $N_{a}$ is the number of fish in age-class $a$. Dividing the number of fish in each age-class by the total number of fish from age 2 up to the oldest age-class with at least one fish provided the expected proportion of fish in each age-class.

Yield-per-recruit analysis.-We constructed a yieldper-recruit model (Quinn and Deriso 1999) to investigate the influence of fishing mortality and selectivity (in the form of 406-, 508-, and 610-mm minimum size limits) on the yield and age composition of striped bass 
harvested from Badin Lake. Yield-per-recruit modeling is an approach best suited to situations in which recruitment is independent of stock size, such as is the case for stocked striped bass populations. Parameterization of the model required information on natural mortality, selectivity, and growth. We used the natural mortality estimated in this study for all age-classes of age 1 and older. All fish above the size limit were assumed to be fully recruited to the fishery with a selectivity of 1 . Growth in length was modeled using a von Bertalanffy growth curve as

$$
L_{t}=797.55 \times\{1-\exp [-0.32 \times(t-(-0.25))]\},
$$

where $L_{t}$ is length at age $t(\mathrm{~mm})$. Growth curve parameters were based on aging of 347 Badin Lake striped bass, as described above, and a subsample of fish randomly selected from each year-class for backcalculation using the Fraser-Lee direct proportion method (Carlander 1982). Back-calculation was performed on 27 fish for a total of 79 estimates of lengthat-annulus production (Thompson et al. 2005). The relationship between length and weight was given as

$$
W=\left(1.35 \times 10^{-5}\right) \times L^{2.97},
$$

where $W$ is weight $(\mathrm{g})$ and $L$ is length $(\mathrm{mm})$. This relationship was based on length and weight data from the 347 fish used in aging, and the relationship had an $R^{2}$ value of 0.97 (Thompson et al. 2005).

The yield-per-recruit model was constructed using monthly periods to reflect the seasonality in fishing mortality observed in this study and to allow seasonal catch-and-release mortality to be incorporated into the model. While annual instantaneous fishing mortality was allowed to vary between 0 and 1 to determine the effect of fishing mortality on the yield and age composition of harvested fish, the proportion of the annual fishing mortality in each month was set equal to the average proportion of fishing mortality in each month of the 2 years of this study. We also included the effect of catch-and-release mortality in the yield-perrecruit model using these monthly periods. Wilde et al. (2000) synthesized data from studies of catch-andrelease mortality of striped bass in freshwater to develop a model predicting percent mortality based on bait type and water temperature. We used the relationship provided for natural baits because anecdotal evidence suggests that many striped bass anglers on Badin Lake use fresh fish bait. For each month, the water temperature used in the model reflected the temperature occupied by striped bass on the 15 th day of each month in 2002 because summer temperatures in 2002 were typical for the system, while those in 2003 were somewhat cooler (Thompson et al. 2005).
Occupied temperatures were determined by applying thermal selection rules, based on thermal selection of the striped bass tagged with temperature sensing transmitters in this study, to temperature and dissolved oxygen profiles conducted at sites across the reservoir (Thompson et al. 2005). We assumed that all age-2 and older fish that were below the size limit would be susceptible to catch-and-release mortality, and we applied the catch-and-release mortality rate to the number of sublegal fish that would have been caught based on the fishing mortality rate for that month. Considering that catch-and-release mortality of striped bass in the summer can be quite high (Wilde et al. 2000), we also conducted yield-per-recruit models with a lower size limit $(406 \mathrm{~mm})$ for June through September and a higher size limit $(508 \mathrm{~mm})$ for the remainder of the year.

\section{Results}

Sixty-four striped bass tagged and found alive in the study area 1 month postsurgery were included in the mortality analysis (Thompson et al. 2005). A total of 35 fish were released between December 2001 and May 2002. The 14 females and 21 males ranged from 473 to $804 \mathrm{~mm}$ TL $($ mean $=535 \mathrm{~mm})$ and from 1,228 to $6,408 \mathrm{~g}$ wet weight (mean $=2,256 \mathrm{~g}$ ). An additional 29 fish entered the study between March and May 2003; these 16 females and 13 males ranged from 425 to $786 \mathrm{~mm} \mathrm{TL}$ (mean $=627 \mathrm{~mm}$ ) and from 936 to $6,810 \mathrm{~g}$ wet weight (mean $=3,374 \mathrm{~g}$ ). Sixteen fish survived from 2002 to 2003, bringing the starting sample size in the spring of 2003 to 45 fish (Thompson et al. 2005). With the exception of the first four search occasions (January-February 2002), which had very low sample sizes (2-4 fish) because of the gradual process of tagging fish, the sample size for each relocation date ranged from 11 to 42 fish and averaged 20.7 fish.

Tagged fish that were collected by electrofishing below Tuckertown Dam moved out of the tailrace in late spring of both years. These fish were distributed throughout the reservoir during the remainder of the year, displaying habitat selection patterns that varied among individuals and appeared to be influenced by environmental conditions, particularly during the summer (Thompson et al. 2005). This movement and redistribution suggest that fish caught in the Tuckertown Dam tailrace were a reasonably random sample of the Badin Lake striped bass population rather than drawing on a particular school or subpopulation. In addition, $50 \%$ of fish surviving from 2002 to 2003 were harvested in the second year compared with $48 \%$ of fish newly tagged in 2003. The similarity in these percentages provides a good indication of mixing of 


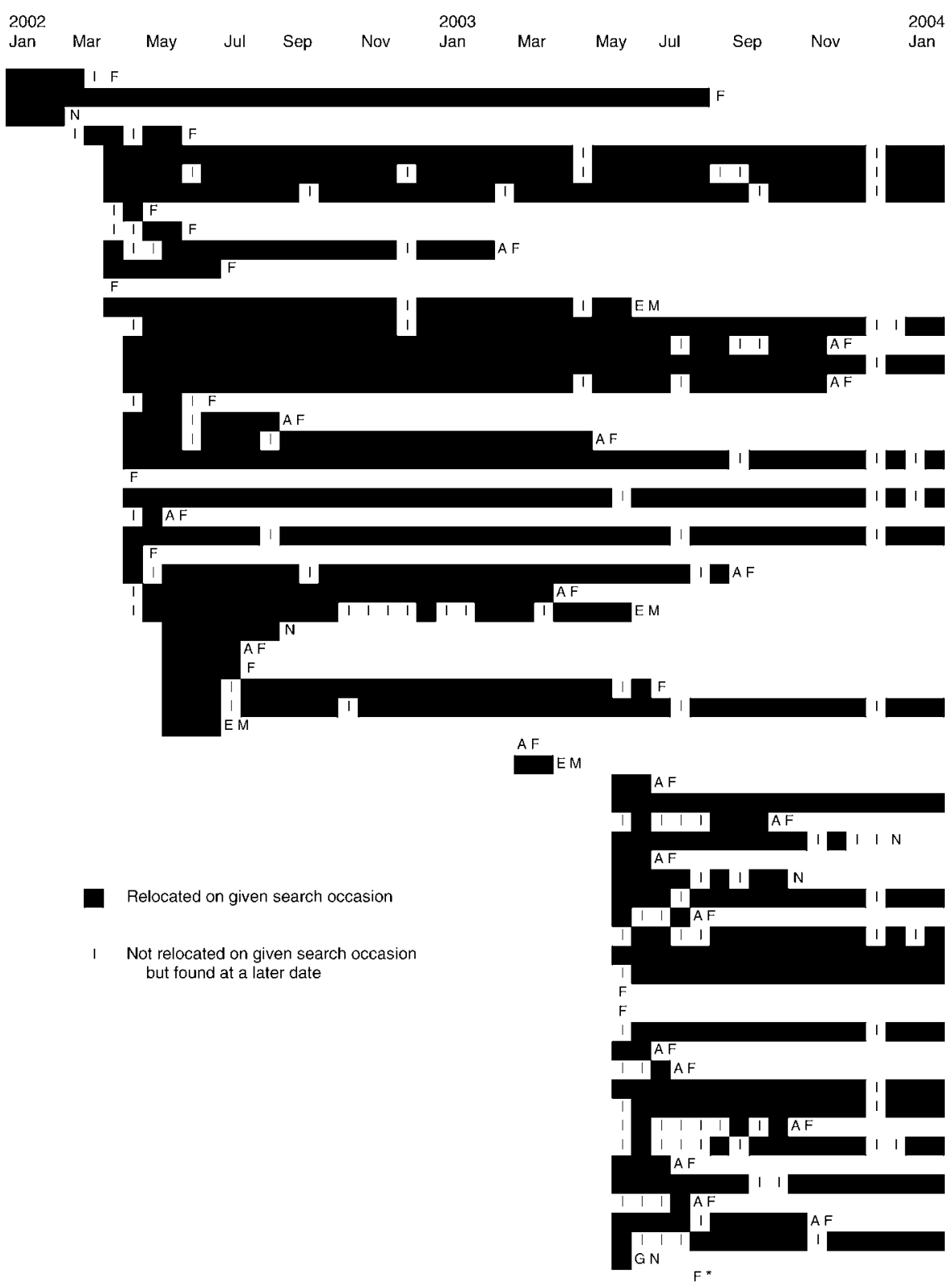

FIGURE 2.- Relocation histories for 64 telemetered striped bass included in the estimation of mortality rates in Badin Lake, North Carolina, 2002-2003. Each row represents the history of a single tagged fish. For individuals not surviving the duration of the study, fates are coded as natural mortality $(\mathrm{N})$, fishing mortality confirmed by angler return $(\mathrm{F})$, assumed fishing mortality based on disappearance from the system (AF), emigration confirmed by relocation in a downstream system (EM), and sacrifice during gill-net sampling (GN). Asterisk indicates a fish implanted with an incorrectly activated transmitter in May 2003. This fish's harvest was confirmed by angler return, so the fish was considered a valid release. It is the only fish for which an accurate date of harvest is dependent on angler information.

tagged fish in the population. Mortality rates estimated from relocations of tagged fish should therefore be applicable to the entire population.

Our analysis indicated that 35 of the 64 fish in the study were harvested (Figure 2). Thirteen harvests occurred in 2002, and 10 of these were confirmed by angler returns. Twenty-two harvests occurred in 2003, but only five of these were confirmed by angler returns. 
TABLE 1.- Values of Akaike information criterion for the 10 best models fit to the Badin Lake (North Carolina) striped bass telemetry data and for the full model that allowed all estimates to vary by biweekly or monthly search occasion. The model with the lowest AIC value is considered the best model. All models allowed relocation probability to vary by search occasion, whereas natural mortality and fishing mortality estimates were grouped over time. The groupings are coded as follows: bimonthly (January-February, MarchApril, etc.); quarter (December-February, March-May, etc.); year (constant within each year); and constant (constant across both years).

\begin{tabular}{llr}
\hline $\begin{array}{c}\text { Fishing } \\
\text { mortality }\end{array}$ & $\begin{array}{c}\text { Natural } \\
\text { mortality }\end{array}$ & $\begin{array}{c}\text { AIC } \\
\text { value }\end{array}$ \\
\hline Quarter & Constant & 384.7 \\
Constant & Constant & 387.6 \\
Year & Constant & 389.6 \\
Quarter & Quarter & 390.1 \\
Quarter & Year & 392.5 \\
Bimonthly & Constant & 392.7 \\
Constant & Quarter & 393.4 \\
Year & Quarter & 395.3 \\
Constant & Year & 395.7 \\
Quarter & Bimonthly & 396.6 \\
Full & Full & 502.9 \\
\hline
\end{tabular}

We cannot explain this difference in tag returns between the 2 years. Initially, we suspected that perhaps the external tags were being shed from fish tagged in 2002 that survived to 2003. However, 2 of the 8 fish tagged in 2002 and harvested in 2003 were reported (tag reporting rate $=25 \%$ ), while 3 of the 14 fish tagged and harvested in 2003 were reported (tag reporting rate $=21 \%$ ); thus, the year of tagging did not appear to affect the chance that an individual fish would be returned. Two of the 15 anglers returning fish reported that they would normally have released the fish but decided to keep it because of the presence of the external tag and the advertised reward for tagged fish; this result indicates that we may have slightly overestimated fishing mortality as a result of using the external tag. The probability of an individual fish being harvested was independent of fish sex (Fisher's exact test: $P=0.45$ ) and TL at tagging (Fisher's exact test: $P=0.11)$.

Only four deaths were attributed to natural causes during the study (Figure 2). Two occurred in 2002, one in early spring and the other in late summer. The remaining two mortalities occurred in fall and early winter 2003.

Five fish were censored in the data analysis (Figure 2 ), meaning that they were not included in the analysis after their last relocation in the system to prevent them from being incorrectly assigned as natural or fishing mortalities. One of these fish died in a gill net during routine sampling of the striped bass population. The other four fish emigrated from the system through Badin Dam and were then found during searches of the downstream reservoirs conducted in June 2002, June 2003, and January 2004. Two fish were relocated in Falls Lake; one of these was last found in Badin Lake in late June 2002, while the other was last found in Badin Lake at the end of March 2003 (Figure 2). Based on their locations, the two fish located in Falls Lake were probably dead, indicating that they may not have survived the passage through Badin Dam. Two fish were also relocated in Lake Tillery; both of these fish were last found in Badin Lake in late June 2003 (Figure 2).

Each of the 10 best models grouped natural and fishing mortality over time periods of 2 months or longer, while the 3 best models held natural mortality constant for the 2 years of the study (Table 1). The model receiving the lowest AIC value allowed fishing mortality to vary by quarter and held natural mortality constant (Table 1). Interestingly, the second-best model held both fishing mortality and natural mortality constant for both years (Table 1). This was probably the result of relatively low numbers of harvests observed in most months, such that the difference between the number of harvests predicted by the constant fishing mortality model and the seasonal fishing mortality model was not large. However, given that harvests appeared to be seasonal and the seasonal fishing mortality model received the lowest AIC value, we selected the model that assumed quarterly fishing mortality and constant natural mortality as the best choice for these data. This model was used to estimate relocation probability and natural and fishing mortality for the Badin Lake striped bass population.

Relocation probability was generally high (Figure 3) and had a mean of 0.89 and a range of 0.24-1.00. Search occasions with particularly low relocation probabilities were often the result of incomplete searches caused by equipment or boat failure. Fishing mortality was highest during the spring and summer 2002 and the summer and fall 2003; estimates of monthly instantaneous fishing mortality, held constant within each quarter, ranged from essentially 0 to almost 0.11 (Figure 3). The precision of the monthly instantaneous fishing mortality rate estimates was similar for most quarters except January-February 2002, March-May 2002, and September-November 2002 (Figure 3). Estimates were more precise in January-February 2002 and September-November 2002 because no harvests were observed during those periods; any fish missed on a particular search occasion because of a relocation probability less than 1.0 was seen again on a later occasion. The monthly estimate was slightly less precise in March-May 2002 because 

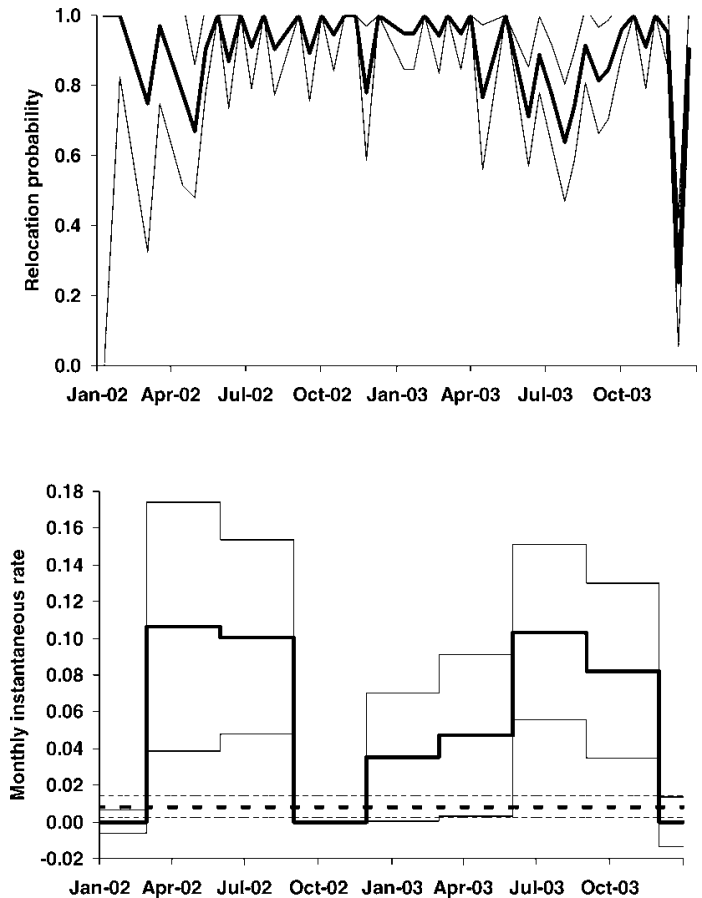

FIGURE 3.-Estimated relocation probability (upper panel), fishing mortality rate ( $F$; bottom panel, solid line), and natural mortality rate ( $M$; bottom panel, dotted line) of Badin Lake (North Carolina) striped bass in 2002 and 2003 based on the model providing the best fit to telemetry relocation data. Relocation probabilities are presented for each search occasion; mortality rates are presented as monthly instantaneous rates held constant during each quarter $(F)$ or over both years of the study $(M)$. Thick lines are estimates, and thin lines are $95 \%$ confidence intervals.

many fish were tagged toward the end of this quarter, so the sample size at the beginning of the quarter was fairly low and numerous harvests were observed during this time. Annual instantaneous fishing mortality $( \pm \mathrm{SE})$ was $0.65 \pm 0.08$ in 2002 and $0.77 \pm 0.08$ in 2003. These instantaneous rates correspond to about $46 \%$ annual mortality due to fishing in 2002 and $51 \%$ annual mortality due to fishing in 2003. Annual instantaneous natural mortality for both years was $0.10 \pm 0.01$, which corresponds to about $7 \%$ annual mortality due to natural causes in each year. These estimates result in an annual instantaneous total mortality of $0.75 \pm 0.08$ for 2002 and $0.87 \pm 0.08$ for 2003, which correspond to annual mortality rates of $53 \%$ (annual survival $=47 \%$ ) and $58 \%$ (annual survival $=42 \%$ ), respectively.

Emigration represents a loss to the stocked population that may be of interest to managers. To investigate how emigration affects survival rate estimates, the telemetry data were also reanalyzed with emigration
TABLE 2.-Annual estimates of instantaneous fishing mortality $(F)$ and exploitation rate $(U)$ based on censoring up to $50 \%$ of assumed Badin Lake (North Carolina) striped bass harvests in 2003. The percent change in $F$ and $U$ indicates the reduction in those rates as a result of the associated reduction in the number of assumed harvests.

\begin{tabular}{|c|c|c|c|c|c|}
\hline \multicolumn{2}{|c|}{ Fish censored } & \multicolumn{2}{|c|}{$F$} & \multicolumn{2}{|c|}{$U(\%)$} \\
\hline Number & $\begin{array}{l}\text { Percent } \\
\text { change }\end{array}$ & Estimate & $\begin{array}{l}\text { Percent } \\
\text { change }\end{array}$ & Estimate & $\begin{array}{l}\text { Percent } \\
\text { change }\end{array}$ \\
\hline 0 & 0.0 & 0.768 & 0.0 & 51.4 & 0.0 \\
\hline 1 & 4.5 & 0.739 & 3.8 & 50.0 & 2.6 \\
\hline 2 & 9.1 & 0.709 & 7.7 & 48.7 & 5.3 \\
\hline 3 & 13.6 & 0.669 & 12.9 & 46.7 & 9.1 \\
\hline 4 & 18.2 & 0.631 & 17.8 & 44.8 & 12.8 \\
\hline 5 & 22.7 & 0.603 & 21.5 & 43.4 & 15.6 \\
\hline 6 & 27.3 & 0.574 & 25.3 & 41.8 & 18.7 \\
\hline 7 & 31.8 & 0.533 & 30.6 & 39.5 & 23.1 \\
\hline 8 & 36.4 & 0.493 & 35.8 & 37.2 & 27.6 \\
\hline 9 & 40.9 & 0.458 & 40.4 & 35.1 & 31.6 \\
\hline 10 & 45.5 & 0.411 & 46.6 & 32.2 & 37.4 \\
\hline 11 & 50.0 & 0.379 & 50.6 & 30.2 & 41.3 \\
\hline
\end{tabular}

included as a source of "mortality." Two fish emigrated in each year of the study, and their inclusion in the analysis reduced the annual survival rate from $47 \%$ to $43 \%$ in 2002 and from $42 \%$ to $38 \%$ in 2003 . While we consider it unlikely becuase of the thoroughness of our downstream searches, it is possible that other fish missing from the system emigrated downstream but were not relocated during searches of the downstream reservoirs. These fish would have been incorrectly assigned as fishing mortalities such that the fishing mortality rate would be overestimated. However, their disappearance represents a loss to the system such that these recalculated total annual survival rates, including natural mortality, harvest, and emigration, would still be correct.

\section{Effect of Errors in Assumed Fish Fates on Fishing Mortality Estimates}

The percent reduction in estimates of annual instantaneous fishing mortality for 2003 was proportional to the percent reduction in the number of assumed harvests when up to $50 \%$ of assumed harvests for the year were censored (Table 2). The percent reduction in exploitation rates (i.e., percentage of annual mortality due to fishing) was slightly less than the percent reduction in the number of assumed harvests (Table 2). Similarly, for quarters 1, 3, and 4 in 2003, the percent reduction in estimates of monthly instantaneous fishing mortality was proportional to the percent reduction in the number of assumed harvests when up to $50 \%$ of assumed harvests in each quarter were censored (Table 3). For these quarters, the release date on which the harvested fish were censored did not affect the new estimate of fishing mortality. For quarter 
TABLE 3.-Monthly estimates of instantaneous fishing mortality $(F)$ of Badin Lake (North Carolina) striped bass for quarters $1-4$ in 2003 based on censoring up to $50 \%$ of assumed harvests in each quarter. Percent change in $F$ indicates the reduction due to the associated reduction in number of assumed harvests. For quarter 2, two estimates of $F$ are given for each number of fish censored; the first is based on censoring fish from the first half of the quarter, when the sample size was small, while the second is based on censoring fish from the second half of the quarter, when the sample size was large (see text).

\begin{tabular}{ccccccc}
\hline & & \multicolumn{2}{c}{ Fish censored } & & \multicolumn{2}{c}{$F$} \\
\cline { 3 - 4 } Quarter & Original $F$ & Number & $\begin{array}{c}\text { Percent } \\
\text { change }\end{array}$ & & Estimate & $\begin{array}{c}\text { Percent } \\
\text { change }\end{array}$ \\
\hline 1 & 0.035 & 1 & 50.0 & 0.018 & 49.4 \\
2 & 0.047 & 1 & 25.0 & & $0.028,0.038$ & $39.9,19.3$ \\
2 & 0.047 & 2 & 50.0 & & $0.021,0.030$ & $55.7,36.2$ \\
3 & 0.103 & 1 & 10.0 & & 0.093 & 10.2 \\
3 & 0.103 & 2 & 20.0 & & 0.082 & 20.6 \\
3 & 0.103 & 3 & 30.0 & & 0.072 & 30.3 \\
3 & 0.103 & 4 & 40.0 & & 0.062 & 40.3 \\
3 & 0.103 & 5 & 50.0 & & 0.051 & 50.6 \\
4 & 0.082 & 1 & 16.7 & & 0.069 & 16.5 \\
4 & 0.082 & 2 & 33.3 & & 0.055 & 33.1 \\
4 & 0.082 & 3 & 50.0 & & 0.041 & 49.7 \\
\hline
\end{tabular}

2, however, the release date on which fish were censored affected the estimate of fishing mortality. A large number of fish were tagged and released about halfway through this quarter, so the sample size varied greatly between early release dates (when sample sizes were low) and later release dates (when samples sizes were larger than at any other point in the study). Censoring fish on early release dates resulted in a greater percent reduction in the estimate of fishing mortality than the percent reduction in the number of fish harvested, while censoring fish on later release dates resulted in a smaller percent reduction in the estimate of fishing mortality (Table 3). This effect of release date is probably not the result of sensitivity of fishing mortality estimates to sample size because sample size varied between other quarters, and the percent reduction in fishing mortality estimates was always proportional to the percent reduction in assumed harvests. Rather, censoring of a single fish in the first half of quarter 2 represents a larger proportion of the total number of fish on those release dates, resulting in a larger effect on the new estimate of fishing mortality than when fish are censored in the second half of the quarter. Therefore, the results of these analyses provide strong evidence that any error in fishing mortality rates estimated by this telemetrybased approach as a result of incorrectly assigning assumed harvests will be directly proportional to the percent of fish incorrectly assigned.

\section{Observed Age Composition versus Age Composition Estimated Using Mortality Rates}

Observed age composition of age- 2 and older striped bass collected in Badin Lake during 2000 through 2003 was as follows: $54 \%$ were age $2,23 \%$ were age $3,18 \%$ were age $4,3 \%$ were age $5,2 \%$ were age 6 , and $1 \%$ were age 7. Based on $Z$ averaged over the 2 years of this study $(Z=0.81)$, age- 2 and older fish exhibited the following age composition: $56 \%$ were age $2,25 \%$ were age $3,11 \%$ were age $4,5 \%$ were age $5,2 \%$ were age 6 , and $1 \%$ were age 7 . The similarity between the observed and estimated age compositions provides strong evidence that our total mortality rate estimates are within a reasonable range for the Badin Lake population.

\section{Yield-per-Recruit Analysis}

The current yield per recruit for the Badin Lake striped bass fishery was estimated to be $1.44 \mathrm{~kg}$ based on a size limit of $406 \mathrm{~mm}$, an annual instantaneous natural mortality rate of 0.1 , and an annual instantaneous fishing mortality rate of 0.71 (the average of the 2 years of this study). Yield-per-recruit analysis showed that an additional $0.28 \mathrm{~kg} /$ recruit could be gained by reducing the fishing mortality rate to 0.3 (Figure 4). Alternatively, an additional $0.09 \mathrm{~kg} /$ recruit could be gained by increasing the size limit to $508 \mathrm{~mm}$, even if the fishing mortality rate remained at 0.71 (Figure 4). The greatest yield per recruit, $1.81 \mathrm{~kg}$, would be achieved by increasing the size limit to 508 $\mathrm{mm}$ and decreasing the fishing mortality to 0.3 (Figure 4). Increasing the size limit to $610 \mathrm{~mm}$ does not result in greater yield than a $508-\mathrm{mm}$ limit because of the effect of catch-and-release mortality. Badin Lake striped bass require just over a year to grow from 508 to $610 \mathrm{~mm}$, and the population reduction caused by catch-and-release mortality during this time period would offset the gain in yield from the harvest of larger fish.

In addition to increasing yield, an increase in the size 


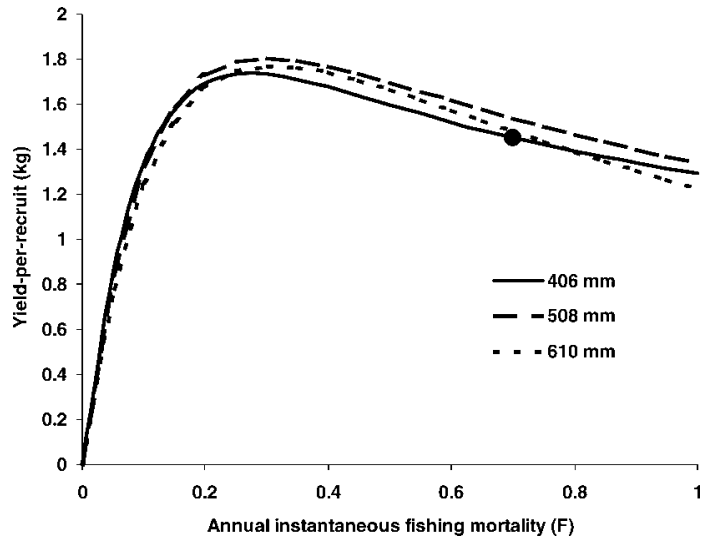

FIGURE 4.-Yield per recruit (kg) for the Badin Lake, North Carolina, striped bass fishery under annual instantaneous fishing mortality rates $(F)$ of $0.0-1.0$ and size limits of 406 (solid line), 508 (dashed line), and $610 \mathrm{~mm}$ (dotted line). For size limits above $406 \mathrm{~mm}$, sublegal fish were subject to catchand-release mortality, as described in the text. The large black dot represents the estimated current state of the fishery (size limit $=406 \mathrm{~mm} ; F=0.71$, the 2002-2003 average).

limit or decrease in fishing mortality would result in a larger proportion of older, larger fish being harvested by Badin Lake striped bass anglers. Under current conditions, yield-per-recruit analysis showed that over $80 \%$ of striped bass harvested are age 2 or 3 (Table 4). Under a 406-mm size limit and a decrease in fishing mortality to 0.3 , the majority of fish harvested would still be age 2 or 3 , but a substantially larger proportion of older fish would be included in the harvest (Table 4). Alternatively, for a fishing mortality rate of 0.71 but a size limit of $508 \mathrm{~mm}$, harvest would again be focused most heavily on the age-classes just past the size limit: almost $80 \%$ of the harvest would be composed of age- 3 and age-4 fish (Table 4). As expected, the most dramatic shift in the age composition of the harvest would occur with a size limit of $508 \mathrm{~mm}$ and a low fishing mortality rate of 0.3 ; under those conditions,
$28.5 \%$ of the harvest would be composed of age- 6 and older fish (Table 4). Increasing the size limit to 508 $\mathrm{mm}$ would result in a $26 \%$ reduction in the number of fish harvested at a fishing mortality rate of 0.71 and a $30 \%$ reduction at a fishing mortality rate of 0.3 compared with current fishery conditions; these reductions in the number of fish harvested were primarily attributable to catch-and-release mortality.

Allowing fish larger than $406 \mathrm{~mm}$ to be harvested during June through September while maintaining a minimum size limit of $508 \mathrm{~mm}$ during the rest of the year would increase the proportion of older, larger fish harvested only slightly if fishing mortality remains high (Table 4). With an annual fishing mortality rate of $0.71,70 \%$ of harvested fish would be age 2 and 3 under the seasonal size limit strategy. When fishing mortality was reduced to 0.3 , the shift in age composition to older fish was more pronounced (Table 4). Allowing harvest of smaller fish that would otherwise experience high catch-and-release mortality resulted in a lower reduction in the number of fish harvested in comparison with current conditions. Only $9 \%$ fewer fish would be harvested at a fishing mortality rate of 0.71 , while $21 \%$ fewer fish would be harvested at a fishing mortality rate of 0.3 .

\section{Discussion}

Natural mortality among striped bass in Badin Lake was very low, while fishing mortality was high and seasonally variable. These results suggest that the fishery would benefit from a different management approach, depending on the goals of fishery managers and the preferences of anglers utilizing the resource. Management approaches taken for recreational striped bass fisheries range from fairly unconstrained harvest (high creel limit, low size limit) of many small fish to stricter regulations (low creel limit, high size limit) allowing harvest of a smaller number of larger fish. The Badin Lake striped bass fishery is currently dominated by harvest of many small fish.

TABLE 4.-Age composition (\% by number) of the Badin Lake (North Carolina) striped bass harvest under different minimum size limits and annual instantaneous fishing mortality rates $(F)$ based on results of a yield-per-recruit model. The seasonal size limit allows for harvest of fish larger than $406 \mathrm{~mm}$ during June-September but those longer than $508 \mathrm{~mm}$ during the remainder of the year. Current fishery conditions are a year-round, 406-mm size limit and an $F$ of 0.71 . The total length (TL) range (mm) for each age-class is based on a von Bertalanffy growth curve for the population $(N=347$ fish; parameters provided in text).

\begin{tabular}{|c|c|c|c|c|c|c|c|}
\hline \multirow[b]{2}{*}{ Age-class } & \multirow[b]{2}{*}{$\mathrm{TL}(\mathrm{mm})$} & \multicolumn{2}{|c|}{$406 \mathrm{~mm}$} & \multicolumn{2}{|c|}{$508 \mathrm{~mm}$} & \multicolumn{2}{|c|}{ Seasonal } \\
\hline & & $F=0.71$ & $F=0.30$ & $F=0.71$ & $F=0.30$ & $F=0.71$ & $F=0.30$ \\
\hline Age 2 & $409-515$ & 55.6 & 33.4 & 2.0 & 1.0 & 34.7 & 19.2 \\
\hline Age 3 & $515-592$ & 24.7 & 22.4 & 54.5 & 33.3 & 36.3 & 27.2 \\
\hline Age 4 & $592-649$ & 11.0 & 15.0 & 24.2 & 22.3 & 16.1 & 18.2 \\
\hline Age 5 & $649-687$ & 4.9 & 10.0 & 10.7 & 14.9 & 7.2 & 12.2 \\
\hline Age $6+$ & $>687$ & 3.8 & 19.2 & 8.6 & 28.5 & 5.7 & 23.3 \\
\hline
\end{tabular}


The yield-per-recruit model for Badin Lake striped bass suggests that a decrease in fishing mortality or a moderate increase in the minimum size limit or both would increase yield. More importantly, these changes would result in a shift from harvest dominated by young fish less than $600 \mathrm{~mm}$ to harvest containing a larger proportion of older, larger fish. This increased yield and increase in harvest of older fish when the size limit was increased from $406 \mathrm{~mm}$ to $508 \mathrm{~mm}$ occur even when accounting for the effect of catch-andrelease mortality of fish smaller than the minimum legal size. Increasing the number of older, larger fish in the population may cause changes in natural mortality and growth because of shifts in predator-prey dynamics that are not captured by the yield-per-recruit model. As with any modification in management strategy, growth rates would need to be monitored to assess these effects. However, we feel that the estimates of natural mortality and seasonal fishing mortality gained in this study provide greater confidence in the yieldper-recruit modeling results than in cases when these rates are unknown.

Our estimate of annual instantaneous natural mortality $(0.10 \pm 0.01)$ was similar to those previously estimated for reservoir populations of striped bass in the southeastern United States. Hightower et al. (2001) found instantaneous natural mortality rates of $0.16 \pm$ 0.04 and $0.12 \pm 0.04$ in the 2 years of their study on Lake Gaston, North Carolina-Virginia. Young and Isely (2004) estimated similar rates of $0.14 \pm 0.02$ and $0.09 \pm 0.02$ in the 2 years of their study of striped bass in J. Strom Thurmond Reservoir, South CarolinaGeorgia. While summer die-offs occasionally occur on Badin Lake, none were observed during the course of our study or during the studies on Lake Gaston or J. Strom Thurmond Reservoir. Therefore, these results suggest that a natural mortality rate of $0.09-0.16$ is a reasonable approximation for other reservoir populations of striped bass, unless a substantial summer mortality event is observed. Having a reasonably narrow range of natural mortality supported by studies of several striped bass populations is important because it allows managers to make use of other approaches, such as catch curve analysis (Quinn and Deriso 1999), to estimate fishing mortality in systems where a telemetry study is not feasible. This range of natural mortality also provides a solid foundation for constructing yield-per-recruit models of other populations for which regulation changes are being considered. Estimating natural mortality in years with summer dieoffs would probably be required on a system-specific basis because summer mortality of striped bass is highly variable across reservoirs in terms of both occurrence and the number of fish involved (Matthews 1985).

The telemetry-based approach to mortality rate estimation does not allow for the differentiation between natural death and catch-and-release mortality. Three of the four deaths that were assumed to be natural mortalities did occur during periods of high estimated fishing mortality, and the possibility that these fish were killed by catch-and-release practices cannot be ruled out. This possibility lends even more strength to the conclusion that natural mortality is very low in this system. The low natural and catch-andrelease mortality rate estimated for Badin Lake striped bass also suggests that catch-and-release practices are currently limited among anglers in this fishery. Fishing mortality was high in the summers of both study years, and the warm summer water temperatures would have led to high mortality of any fish released after angling. The relationship between catch-and-release mortality and water temperature based on the results of seven studies suggests $50-58 \%$ mortality at $27-29^{\circ} \mathrm{C}$ for fish caught on natural baits and 40-48\% mortality for fish caught on artificial baits (Wilde et al. 2000). A recent study on Lake Murray in South Carolina found an even higher mortality rate of $83 \%$ for fish released immediately after angling between June and August (Bettinger et al. 2005). Even with the relatively small number of tagged fish in this study, substantial catchand-release angling would probably have been apparent, given these estimates of catch-and-release mortality and the monthly exploitation rate of $9.5-9.7 \%$ observed during the summer months in the 2 years of this study.

The finding that fishing mortality of Badin Lake striped bass is highest in the summer will be important for fishery managers considering regulation changes that may increase catch-and-release practices, such as an increase in the minimum size limit. Wilde et al. (2000) suggested that managers would find it challenging to enhance striped bass fisheries if fishing effort is high during the summer months. The yieldper-recruit model for the Badin Lake fishery suggests that an increase in the minimum size limit from 406 to $508 \mathrm{~mm}$ would still increase the proportion of larger fish harvested from the fishery, even when catch-andrelease mortality is considered, although the number of fish harvested would decline. Managers may also consider regulations that vary by season, employing a lower size limit during the summer months, when catch-and-release mortality is greatest. Results of the yield-per-recruit model suggest that this strategy will be most effective at increasing harvest of older, larger individuals if the fishing mortality rate is also reduced.

A seasonal trend in fishing mortality was apparent, 
but this trend was not completely consistent between years. The summer represented a period of high harvest in both 2002 and 2003, but the spring of 2002 exhibited high harvest rates while fishing mortality was higher in the fall of 2003. We believe these yearly changes in the seasonality of fishing pressure were related to local events on the reservoir that affected angler behavior. Very low water levels at the end of the summer and into the fall of 2002 closed the boat ramps on the reservoir, preventing anglers from accessing the resource. These closings probably caused the low level of fishing mortality estimated for the fall of 2002 compared with the same season in 2003, when harvest rates were high. Similarly, the spring of 2003 was a period of very high discharge from the upstream dam, resulting in high turbidity and debris in the tailrace, where anglers usually concentrate spring fishing efforts. These conditions may have reduced seasonal fishing pressure compared with 2002. Annual differences in the magnitude and seasonality of fishing mortality have been noted in other studies of reservoir populations of striped bass (Hightower et al. 2001; Young and Isely 2004), and such differences suggest that managers should pay attention to local events, such as low water levels or high spring discharge, when applying fishing mortality rates estimated in 1 year of a mortality study to another year or another system.

Waiting to introduce newly tagged fish into the analysis until the first relocation date 1 month after tagging is an important modification to the technique of estimating mortality rates based on telemetry data. To avoid a potential negative bias in fishing mortality estimates, a quarantine period should be used by researchers whose tagging efforts coincide with periods of high harvest. In our case, considering newly tagged fish that survived the first month posttagging to be available for relocation immediately after tagging reduced estimates of annual instantaneous fishing mortality by 0.07 (to $0.58 \pm 0.07$ ) in 2002 and by 0.03 (to $0.74 \pm 0.07$ ) in 2003 .

We found that 4 of 64 fish emigrated downstream through Badin Dam, providing strong evidence that reservoirs cannot be considered strictly closed systems. Knowledge of the degree of emigration from the population is therefore essential when using the telemetry-based approach to estimate mortality. The structure of the model assumes that fish disappearing from the system are harvested, so fishing mortality will be overestimated if emigrating fish are not removed from the analysis on their last relocation date. Our results are similar to those of Hightower et al. (2001), who found that 2 of 51 striped bass passed downstream through the dam, and Waters et al. (2005), who suspected that 6 of 44 tagged largemouth bass emigrated from Lucchetti Reservoir during a highwater event. In the future, researchers estimating mortality of reservoir fish populations may wish to establish permanent, stationary recording receivers below the downstream dam. These receivers would allow emigration to be estimated more accurately while saving the time associated with searching downstream systems for emigrated fish.

A sensitivity analysis of the 2003 annual and monthly fishing mortality rates showed that the effect of errors in assumed harvests is proportional to the percent change in the number of assumed harvests. Because sample sizes are often low in telemetry studies, this result illustrates the importance of minimizing errors when assigning fish fates. However, it also indicates that erroneous assignment of a small proportion of tagged fish will not result in major errors in estimates of fishing mortality rates. We believe that the probability of incorrect assignment of fish experiencing tag failure as harvested fish in our study was low because no failures were observed among transmitters remaining in the system after natural or surgery-related mortalities. Similarly, the probability of assigning emigrated fish as fishing mortalities was low because of the thoroughness of our downstream searches. The fishing mortality rates estimated in this study should provide an accurate representation of the current fishery and allow managers to begin a dialogue with anglers regarding potential modifications that may increase harvest of larger individuals. The natural mortality rate estimated in this and previous studies of reservoir populations of striped bass should also allow managers to utilize additional techniques to estimate fishing mortality and apply tools, such as yield-perrecruit models, to other systems.

\section{Acknowledgments}

We thank Lawrence Dorsey, Bob Barwick, Rich Fulford, Bill Pine, Wes Neal, Chad Harris, and Suzi Jones for field assistance. Brent Bishop and other anglers on Badin Lake assisted the project through the collection of fish for tagging and return of telemetry tags from harvested fish. This manuscript was improved through discussions with Dave Hewitt, Nate Bacheler, and Randy Jackson and through comments from four anonymous reviewers. Funding was provided by a North Carolina Wildlife Resources Commission grant (Federal Aid in Sport Fish Restoration Project F-68-04) to J.A.R. and J.E.H. Funding was also provided by a Robert M. Jenkins Memorial Reservoir Research Scholarship from the Southern Division of the American Fisheries Society and a National Science Foundation Graduate Research Fellowship to J.S.T. 
Reference to trade names does not imply endorsement by the U.S. Government.

\section{References}

Akaike, H. 1973. Information theory and an extension of the maximum likelihood principle. Pages 267-281 in B. N. Petran and F. Csaaki, editors. Second international symposium on information theory. Akadeemiai Kiadi, Budapest, Hungary.

Anderson, R. O., and R. M. Neumann. 1996. Length, weight, and associated structural indices. Pages 447-481 in B. R. Murphy and D. W. Willis, editors. Fisheries techniques, 2nd edition. American Fisheries Society, Bethesda, Maryland.

Bettinger, J. M., J. R. Tomasso, Jr., and J. J. Isely. 2005. Hooking mortality and physiological responses of striped bass angled in freshwater and held in live-release tubes. North American Journal of Fisheries Management 25:1273-1280.

Brownie, C., D. R. Anderson, K. P. Burnham, and D. S. Robson. 1985. Statistical inference from band-recovery data: a handbook, 2nd edition. U.S. Fish and Wildlife Service Resource Publication 156.

Burnham, K. P., D. R. Anderson, G. C. White, C. Brownie, and K. P. Pollock. 1987. Design and analysis of methods for fish survival experiments based on release-recapture. American Fisheries Society, Monograph 5, Bethesda, Maryland.

Carlander, K. D. 1982. Standard intercepts for calculating length from scale measurements for some centrarchid and percid fishes. Transactions of the American Fisheries Society 111:332-336.

Haeseker, S. L., J. T. Carmichael, and J. E. Hightower. 1996. Summer distribution and condition of striped bass within Albemarle Sound, North Carolina. Transactions of the American Fisheries Society 125:690-704.

Heupel, M. R., and C. A. Simpfendorfer. 2002. Estimation of mortality of juvenile blacktip sharks, Carcharhinus limbatus, within a nursery area using telemetry data. Canadian Journal of Fisheries and Aquatic Sciences 59:624-632.

Hightower, J. E., J. R. Jackson, and K. H. Pollock. 2001. Use of telemetry methods to estimate natural and fishing mortality of striped bass in Lake Gaston, North Carolina. Transactions of the American Fisheries Society 130: 557-567.

Hoenig, J. M., N. J. Barrowman, W. S. Hearn, and K. H. Pollock. 1998a. Multiyear tagging studies incorporating fishing effort data. Canadian Journal of Fisheries and Aquatic Sciences 55:1466-1476.

Hoenig, J. M., N. J. Barrowman, K. H. Pollock, E. N. Brooks, W. S. Hearn, and T. Polacheck. 1998b. Models for tagging data that allow for incomplete mixing of newly tagged animals. Canadian Journal of Fisheries and Aquatic Sciences 55:1477-1483.

Matthews, W. J. 1985. Summer mortality of striped bass in reservoirs of the United States. Transactions of the American Fisheries Society 114:62-66.
Ney, J. J. 1999. Practical use of biological statistics. Pages 167-191 in C. C. Kohler and W. A. Hubert, editors. Inland fisheries management in North America, 2nd edition. American Fisheries Society, Bethesda, Maryland.

Pollock, K. H., C. M. Bunck, S. R. Winterstein, and C. L. Chen. 1995. A capture-recapture survival analysis model for radio-tagged animals. Journal of Applied Statistics 22:661-672.

Pollock, K. H., J. M. Hoenig, W. S. Hearn, and B. Calingaert. 2001. Tag reporting rate estimation: 1 . An evaluation of the high-reward tagging method. North American Journal of Fisheries Management 21:521-532.

Pollock, K. H., J. M. Hoenig, and C. M. Jones. 1991. Estimation of fishing and natural mortality when a tagging study is combined with a creel survey or port sampling. Pages 423-434 in D. Guthrie, J. M. Hoenig, M. Holliday, C. M. Jones, M. J. Mills, S. A. Moberly, K. H. Pollock, and D. R. Talhelm, editors. Creel and angler surveys in fisheries management. American Fisheries Society, Symposium 12, Bethesda, Maryland.

Pollock, K. H., H. Jiang, and J. E. Hightower. 2004. Combining telemetry and fisheries tagging models to estimate fishing and natural mortality rates. Transactions of the American Fisheries Society 133:639-648.

Pollock, K. H., S. R. Winterstein, and M. J. Conroy. 1989. Estimation and analysis of survival distributions for radio-tagged animals. Biometrics 45:99-109.

Quinn, T. J. II, and R. B. Deriso 1999. Quantitative fish dynamics. Oxford University Press, Oxford, UK.

Trent, T. T., and O. J. Rongstad. 1974. Home range and survival of cottontail rabbits in southwestern Wisconsin. Journal of Wildlife Management 38:459-472.

Vetter, E. F. 1988. Estimation of natural mortality in fish stocks: a review. U.S. National Marine Fisheries Service Fishery Bulletin 86:25-43.

Walsh, M. G., K. A. Bjorgo, and J. J. Isely. 2000. Effects of implantation method and temperature on mortality and loss of simulated transmitters in hybrid striped bass. Transactions of the American Fisheries Society 129: 539-544.

Waters, D. S., R. L. Noble, and J. E. Hightower. 2005. Fishing and natural mortality of adult largemouth bass in a tropical reservoir. Transactions of the American Fisheries Society 134:563-571.

White, G. C. 1983. Numerical estimation of survival rates from band recovery and biotelemetry data. Journal of Wildlife Management 47:716-728.

Wilde, G. R., M. I. Muoneke, P. W. Bettoli, K. L. Nelson, and B. T. Hysmith. 2000. Bait and temperature effects on striped bass hooking mortality in freshwater. North American Journal of Fisheries Management 20:810-815.

Williams, B. K., J. D. Nichols, and M. J. Conroy. 2002. Analysis and management of animal populations. Academic Press, San Diego, California.

Young, S. P., and J. J. Isely. 2004. Temporal and spatial estimates of adult striped bass mortality from telemetry and transmitter return data. North American Journal of Fisheries Management 24:1112-1119. 